The E.R.A. 246 is a member of the West African Linguistic Society and comprises the following sections:

Grammatical typology; Dialectology; Oral and written literature; Cultural ethnolinguistics (formerly called 'Language and Culture').

A report is given for each section, together with a description of the researches of individual members and research with other groups with which members have been associated. Plans are given for 1973-4 and there is a report on a programme of studies on West Atlantic Languages, also a list of publications by members of the team.

\title{
Socio-Musical Research among the Shangana-Tsonga of South-East Africa
}

Dr. Thomas F. Johnston has recently completed a socio-musical research project on the Shangana-Tsonga of Mozambique and the Northern Transvaal, under the auspices of the Wenner-Gren Foundation for Anthropological Research and the University of the Witwatersrand. Dr. Johnston lived with Tsonga musical specialists for the period I $968-70$ and studied indigenous musical concepts and behaviour and associated social institutions. His report, which includes 33 figures, 210 musical transcriptions, roo plates (mostly in colour), a bibliography, and three reels of recorded tape, is available from the Sociology/ Anthropology Department, Western Washington State College, Bellingham, Washington, or from the library of the University of the Witwaterstand, Johannesburg.

\section{Teaching of Anthropology in Belgium}

A postgraduate Special Diploma in Social and Cultural Anthropology is now offered at the Katholieke Universiteit te Leuven (K.U.L.) in the Faculty of Psychology and Pedagogical Sciences. The one-year programme is conducted in Dutch and includes $I_{3}$ hours of instruction a week and the writing of a thesis. To be eligible for admission students must be holders of a licentiate degree in a human science or of an equivalent degree. Admissions are decided upon by the Faculty Board. The teaching staff includes Professors E. Roosens and W. Claeys (both on the staff of the Faculty of Psychology), an Extraordinary Lecturer (A. Maesen, Head of the Department of Cultural Anthropology at the Royal Museum of Central Africa, Tervuren), and a Reader (M. d'Hertefelt, Head of the Section of Social Anthropology and Ethnohistory at the same Museum). Professor E. Roosens is the coordinator of the programme. The postgraduate curriculum is to be extended by the duplication in English of the Special Diploma and by the addition of a second year of instruction, also in English, which would lead to a postgraduate licentiate degree in Social and Cultural Anthropology. Address of the coordinator: Leopoldstraat 26, 3000 Leuven, Belgium.

\section{Centre for Nigerian Cultural Studies}

Abdultahi Bayero College's Centre for Nigerian Cultural Studies has been established since July 1972 at Gidan Makama, the traditional house of the Makama of Kano. The College is part of Ahmadu Bello University whose headquarters are in Zaria. The Director of the Centre is Professor Michael Crowder, Professor of History at Abdullahi Bayero, and the Executive Secretary Musa Baba Idris, at present engaged in research into the pre-colonial history of Borgu emirate.

Mr. Ade Obayemi is conducting excavations in the Kabba Division of Kwara State and Dr. Fremont Besmer is making a study of the royal musicians of Kano and a comparison of the musical styles of Kano and Bornu. Theatre and dance programmes are also being developed at the centre. 